\title{
Evaluation of flotation process course on the example of sulphide ores
}

\author{
Konrad Oleksik ${ }^{1, *}$, Daniel Saramak ${ }^{1}$, and Anna Młynarczykowska ${ }^{1}$ \\ ${ }^{1} \mathrm{AGH}$, University of Science and Technology, Faculty of Mining and Geoengineering, Department of Mineral Processing and \\ Environmental Engineering
}

\begin{abstract}
The article concerns investigations over the influence of selected parameters of the flotation process course on the values of technological indices of beneficiation process assessment. Following parameters were under evaluation: the pulp density, pulp aeration (measured through the rotational speed of rotor) as well as dosage of flotation reagents. Four technological indices were registered: concentrate recovery, concentrate grade, yield of the concentrate and the tails grade. There were calculated correlation coefficients between selected parameters of flotation process course and the values of technological indices, along with determination of significance of these coefficient, at accepted probability level 0.95 . In the next stage of investigations there were determined mathematical models with the concentrate recovery, concentrate grade, yield of concentrate and tails grade as the functions of pulp density, speed of the rotor and dosage of flotation reagent. On the basis of the investigations carried out, it was appeared that the dosage of flotation reagent was of the most significant influence on the values of technological indices of flotation process assessment. The least significant influence, in turn, was obtained for the pulp density.
\end{abstract}

\section{Introduction}

Flotation is the operation commonly applied in beneficiation of sulphide copper ores. The process is complex and its performance depends on a certain number of parameters, connected with both the feed material, and the process conditions. According to the literature, concerning the issue, following parameters are of significant importance on the obtained values of concentrate grade and recovery:

- pulp density,

- type and dosage of flotation reagents,

- pulp aeration,

- time and layout of flotation course,

- the grade of useful mineral liberation

- particle size of feed.

Pulp density influences the effectiveness of flotation. Together with increasing of the pulp density a linear increase in yields of concentrates can be observed, while the concentrate grades are decreasing [4].

The flotation reagents type and dosage has a strong effect on the course of flotation process. Proper analysis of type and dosages of collector and frother can improve the recovery of useful minerals [18]. Appropriate selection of the reagents regimen results in increasing the quality of flotation concentrates [9]. Results of numerous investigations show that increasing of collector dosage influences the higher concentrate recovery, but only to a certain level. Further increasing of dosage has very limited influence on improvement of flotation process effectiveness [6, 19, 21].

\footnotetext{
*Corresponding author: koleksik@agh.edu.pl
}

Together with increasing of aeration, the probability of collision of air bubble with particles of useful mineral increases too. Probability of adhesion of the air bubble and mineral particle depends on their volumes. Fine particles float more easily in the presence of fine air bubbles, while coarser particles require larger air bubbles $[1-3,11,17]$. While the rotor speed is constant, increasing of the air flow results with increasing the size of the bubbles Furthermore, aeration is influenced by the rotor speed. Increasing the rotor speed results in reduction of air bubbles size, while their number is increased [7, 8]. Furthermore, an increase in rotational speed of rotor results in increasing of concentrate recovery [4].

Results of various investigations $[1,2,5,11,20]$ shows that depending on the type of ore under examination, the material particle size, for which the maximum values of recovery can be obtained, is within the size range $0,020-0,070 \mathrm{~mm}$. Coarser particles might be too heavy to be able transferred into the froth product, while too fine particles, despite the high mineral liberation grade, might pass into waste, which result in decreasing the effectiveness of the flotation process course. $[11,15$, 16]. It is worth mentioning that it is possible to obtain a high recovery of fine particles in flotation circuits, when they are designed particularly for the fines [10]. Furthermore, the mineral liberation grade is connected with the particle size distribution of feed and it affects the effectiveness of flotation process course. Liberation of useful mineral is strictly related to the course of comminution operations, the type of crushing and grinding devices applied and the layout of comminution 
circuit $[12,13]$. Properties of feed material also plays significant role in effectiveness of comminution process course [14].

The article presents selected problems connected with the course of flotation process for various values of the selected parameters, that influence its effectiveness. The effectiveness was measured through the obtained values of concentrate recovery, concentrate grade, as well as tails grade.

\section{Scope of investigations}

The aim of the paper was to test and determine optimal parameters of flotation process course, for sulphide copper ore. Several parameters were selected for testing:

- pulp density,

- rotor speed,

- dosage of flotation collector.

As it was mentioned the above, only the selected parameters were under investigation, and they were accepted for tests on the basis of literature studies. It is worth to underline that the material particle size was not tested in this investigative programme. It was assumed, and accepted, that maximum particle size for the material in flotation tests is below $0,071 \mathrm{~mm}$. The feed material was a copper ore with following lithological composition: carbonates $70 \%$, sandstones $20 \%$, shales $10 \%$, and average feed copper grade $(\alpha)$ was $1,5 \%$. The ore was crushed and grinded for flotation test in a two-stage laboratory-scale comminution circuit:

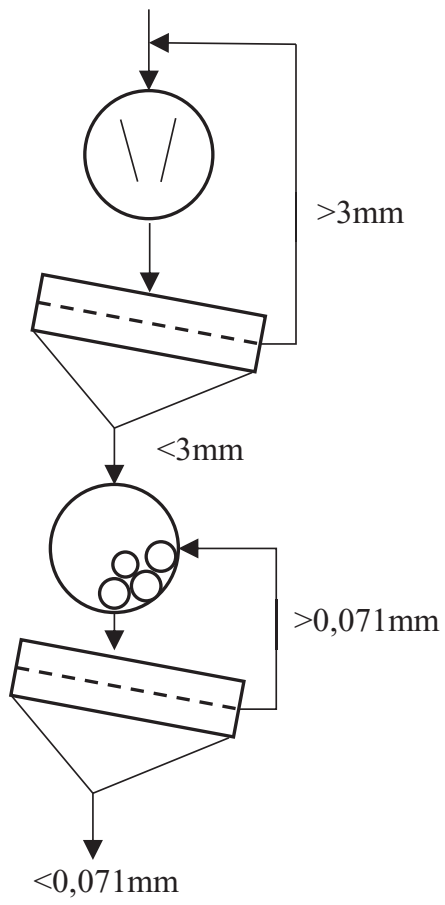

Fig. 1. Scheme of comminution circuit.

The final product from comminution circuits was then divided into 12 representative samples for flotation process.
Flotation was performed in a laboratory pneumaticmechanical machine, Denver type, with $1 \mathrm{dm}^{3}$ volume, as the rough flotation with a single fractioned flotation. Froth products were collected after 1, 3, 5, 10 and 15 minutes. Scheme of flotation results was presented in Figure 2.

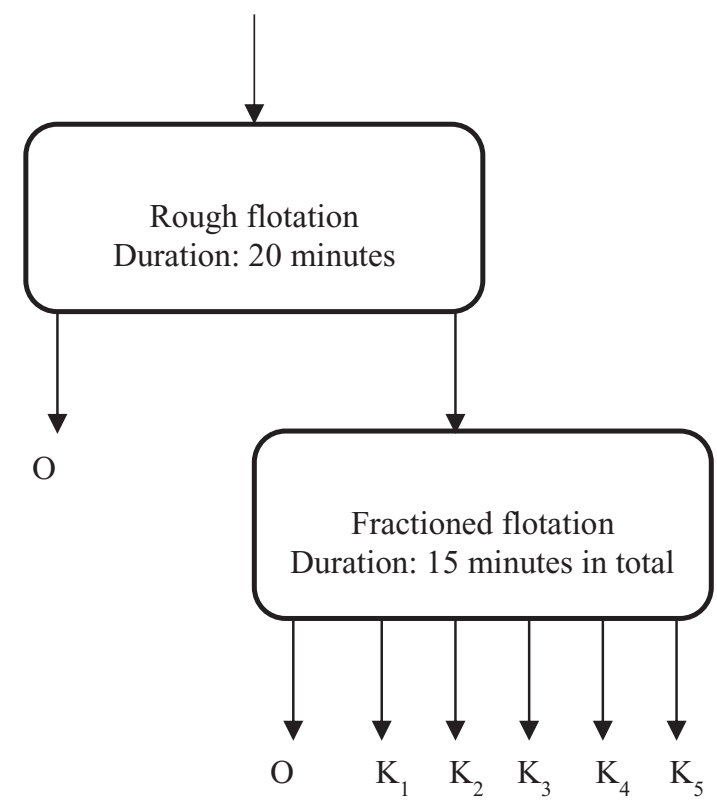

Fig. 2. Scheme of time and layout of flotation course.

The ethyl xanthate sodium was used as a collector in the process, and Nasfroth as a frother reagent. Twelve flotation tests were performed in total, and Table 1. summarizes the values of variable process parameters under investigation. The remaining conditions of the process were kept constant and the dosage of frother reagent was $30 \mathrm{~g} / \mathrm{Mg}$ for each flotation test.

Table 1. Variable values of parameters for each flotation test.

\begin{tabular}{|c|c|c|c|}
\hline $\begin{array}{c}\text { Number of } \\
\text { flotation } \\
\text { test }\end{array}$ & $\begin{array}{c}\text { Pulp } \\
\text { density } \\
{\left[\mathbf{g} / \mathbf{d m}^{3}\right]}\end{array}$ & $\begin{array}{c}\text { Rotor } \\
\text { speed } \\
{[\mathbf{r p m}]}\end{array}$ & $\begin{array}{c}\text { Dosage of } \\
\text { collector } \\
\text { [g/Mg] }\end{array}$ \\
\hline $\mathbf{1}$ & 1100 & 1850 & 85 \\
\hline $\mathbf{2}$ & 1100 & 1850 & 100 \\
\hline $\mathbf{3}$ & 1100 & 1850 & 115 \\
\hline $\mathbf{4}$ & 1200 & 2450 & 85 \\
\hline $\mathbf{5}$ & 1200 & 2450 & 100 \\
\hline $\mathbf{6}$ & 1200 & 2450 & 115 \\
\hline $\mathbf{7}$ & 1100 & 2450 & 85 \\
\hline $\mathbf{8}$ & 1100 & 2450 & 100 \\
\hline $\mathbf{9}$ & 1100 & 2450 & 115 \\
\hline $\mathbf{1 0}$ & 1200 & 1850 & 85 \\
\hline $\mathbf{1 1}$ & 1200 & 1850 & 100 \\
\hline $\mathbf{1 2}$ & 1200 & 1850 & 115 \\
\hline
\end{tabular}

\section{Analysis of results}

For each flotation test there were determined the yields of concentrates $(\gamma)$, concentrate grades $(\beta)$, flotation recoveries $\left(\varepsilon_{\mathrm{k}}\right)$, as well as tail grades $(\vartheta)$. The XRF analyzer was used for determination of copper contents in flotation concentrates and tails. Complete results are presented in Table 2 . 
Table 2. Values of selected technological indicators for copper ore flotation.

\begin{tabular}{|c|c|c|c|c|}
\hline $\begin{array}{c}\text { Number of } \\
\text { flotation test }\end{array}$ & $\boldsymbol{\varepsilon}_{\mathbf{k}}[\mathbf{\%}]$ & $\boldsymbol{\beta}[\mathbf{\%}]$ & $\boldsymbol{9}[\mathbf{\%}]$ & $\boldsymbol{\gamma}[\mathbf{\%}]$ \\
\hline $\mathbf{1}$ & 81.27 & 10.99 & 0.396 & 17.44 \\
\hline $\mathbf{2}$ & 86.30 & 9.29 & 0.314 & 24.15 \\
\hline $\mathbf{3}$ & 86.56 & 7.07 & 0.345 & 31.7 \\
\hline $\mathbf{4}$ & 80.69 & 10.89 & 0.415 & 19.35 \\
\hline $\mathbf{5}$ & 84.41 & 8.94 & 0.396 & 27.57 \\
\hline $\mathbf{6}$ & 87.15 & 7.91 & 0.317 & 29.17 \\
\hline $\mathbf{7}$ & 81.67 & 10.72 & 0.418 & 21.33 \\
\hline $\mathbf{8}$ & 84.84 & 8.22 & 0.357 & 27.63 \\
\hline $\mathbf{9}$ & 84.14 & 7.98 & 0.376 & 28.11 \\
\hline $\mathbf{1 0}$ & 83.46 & 9.07 & 0.374 & 22.60 \\
\hline $\mathbf{1 1}$ & 87.00 & 7.74 & 0.327 & 29.36 \\
\hline $\mathbf{1 2}$ & 88.95 & 5.56 & 0.317 & 39.99 \\
\hline
\end{tabular}

In the next stage of investigation there were determined quantitative relationships among parameters of process course and the obtained results. Suitable models were calculated with using the multiple regression methods.

Prior to determination of the models, there were calculated the values of correlation coefficients between the selected parameters of flotation process course and values of technological indicators for flotation process run (Table 3.). Statistically significant coefficients at accepted probability level $\alpha=0,05$, were underlined. The results presented in Table 3 show that the collector dosage is of the strongest influence on values of all technological indicators, that is: the yields of concentrates $(\gamma)$, concentrates grades $(\beta)$, flotation recoveries $\left(\varepsilon_{\mathrm{k}}\right)$, and tail grades $(\vartheta)$. Speed of rotor show less strong correlation, while the pulp density has the lowest influence on values of technological indicators.

Table 3. Coefficients of correlation between all variables.

\begin{tabular}{|c|c|c|c|c|}
\hline & $\mathbf{\varepsilon k}[\mathbf{\%}]$ & $\boldsymbol{\beta}[\%]$ & $\boldsymbol{9}[\mathbf{\%}]$ & $\gamma[\%]$ \\
\hline $\begin{array}{c}\text { Pulp density } \\
{\left[\mathbf{g} / \mathbf{d m}^{3}\right]}\end{array}$ & 0.230 & -0.221 & -0.135 & 0.252 \\
\hline $\begin{array}{c}\text { Rotor speed } \\
{[\mathbf{r p m}]}\end{array}$ & -0.356 & 0.263 & 0.463 & -0.172 \\
\hline $\begin{array}{c}\text { Dosage of } \\
\text { collector } \\
\text { [g/Mg] }\end{array}$ & $\underline{0.808}$ & $\underline{-0.856}$ & $\underline{-0.683}$ & $\underline{0.843}$ \\
\hline
\end{tabular}

An influence of dosage of collector and the rotational speed of rotor at the pulp density of $1100 \mathrm{~g} / \mathrm{dm}^{3}$, were presented in Figs. $3-6$. Analysing the results it can be noticed that increase in the dosage of collector results in increase of flotation recovery $\left(\varepsilon_{\mathrm{k}}\right)$ and concentrate yield $(\gamma)$ but causes decrease of concentrate $(\beta)$ and tail $(\vartheta)$ grades

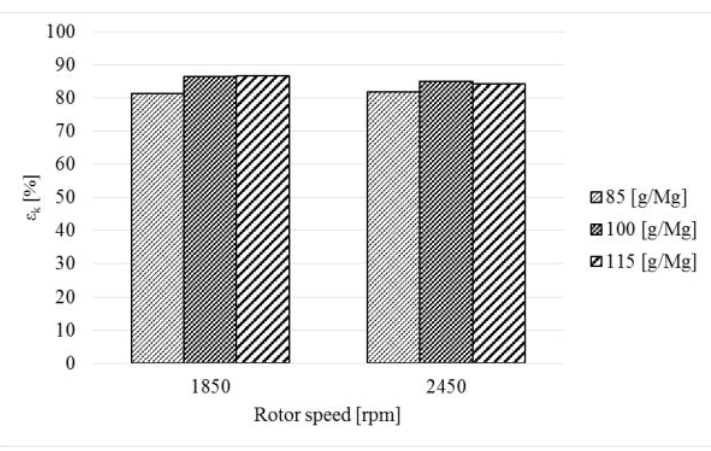

Fig. 3. Flotation recoveries $\left(\varepsilon_{\mathrm{k}}\right)$ in relationship with various values of rotor speed and dosage of flotation collector for pulp density $1100 \mathrm{~g} / \mathrm{dm}^{3}$.

15

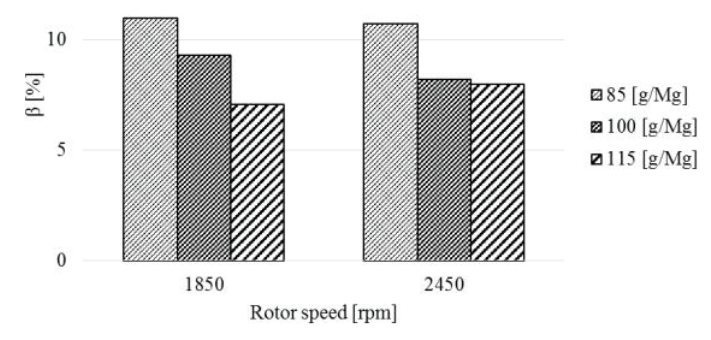

Fig. 4. Concentrates grades $(\beta)$ in relationship with various values of rotor speed and dosage of flotation collector for pulp density $1100 \mathrm{~g} / \mathrm{dm}^{3}$.

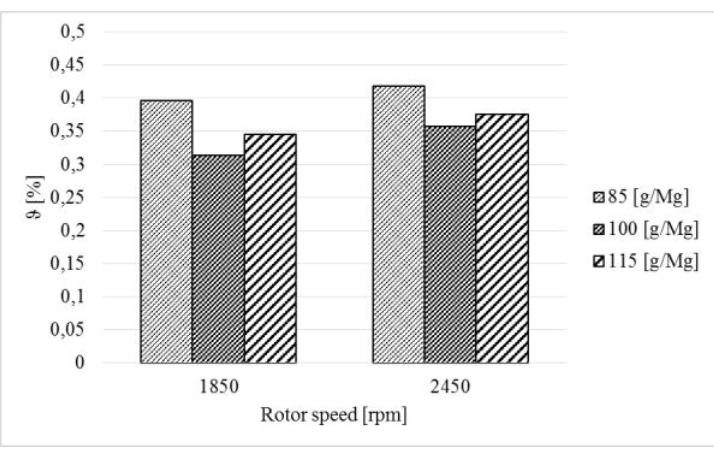

Fig. 5. Tail grades $(\vartheta)$ in relationship with various values of rotor speed and dosage of flotation collector for pulp density $1100 \mathrm{~g} / \mathrm{dm}^{3}$.

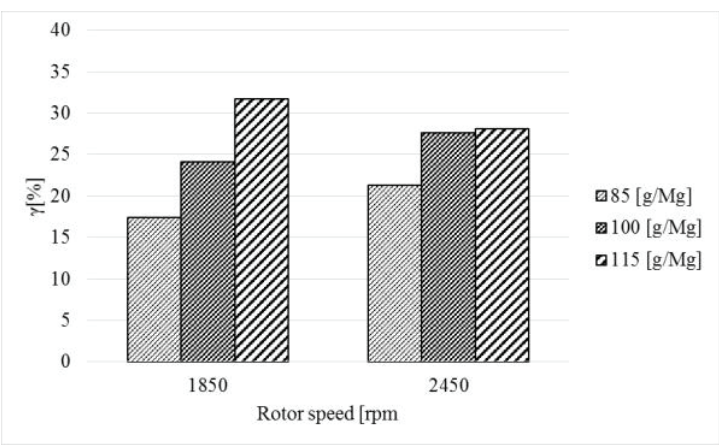

Fig. 6. Yields of concentrates $(\gamma)$, in relationship with various values of rotor speed and dosage of flotation collector for pulp density $1100 \mathrm{~g} / \mathrm{dm}^{3}$. 
The models, linking the values of parameters of flotation process course with the values of selected technological indicators, were determined with using the multiple regression method. The pulp density, rotor speed and dosage of collector were independent variables in the model. Separate models were calculated for the concentrate recovery, concentrate grade, as well as tails grade. Values statistically significant were underlined.

$$
\begin{gathered}
\varepsilon_{k}=61,45+0,0115 a-\underline{0,0030 b}+\underline{0,1643 c} \\
\beta=24,68-0,0069 a+0,0014 b-\underline{0,1096 c} \\
\vartheta=0,56-0,0001 a+\underline{0,00006 b}-\underline{0,0021 c} \\
\gamma=-40,35+0,0295 a-\underline{0,0034 b}+0,4021 c
\end{gathered}
$$

where:

- $\quad \mathrm{a}-$ Pulp density $\left[\mathrm{g} / \mathrm{dm}^{3}\right]$

- $\quad b-$ Rotor speed [rpm]

- $\quad$ - Dosage of collector $[\mathrm{g} / \mathrm{Mg}]$

There were also determined values of $R^{2}$ that characterize the fitting of model:

- $\mathrm{R}^{2}=83,3 \%$ for equation (1)

- $\mathrm{R}^{2}=85,1 \%$ for equation (2)

- $\mathrm{R}^{2}=69,9 \%$ for equation (3)

- $\mathrm{R}^{2}=80,3 \%$ for equation (4)

Both in model one $\left(\varepsilon_{\mathrm{k}}\right)$ and two $(\beta)$ there were achieved the fitting on satisfactory level, while for model number three $(\vartheta)$ the fitting level was lower.

\section{Summary}

The results of flotation tests and statistical analyzes confirm that the tested factors influence the effectiveness of the flotation process. The most significant effect shows the dose of collecting reagent. Its growth causes an increase in flotation recovery $\left(\varepsilon_{\mathrm{k}}\right)$ and yield of concentrate $(\gamma)$ and decrease in concentrates $(\beta)$ and tail grades $(\theta)$. However, it should be pointed out that, according to the literature $[6,19,21,22]$, this effect is only visible to a certain boundary level of the collector, which was not achieved in these tests.

Concentrates with the highest content of the useful ingredient $(\beta)$ were obtained at a collection reagent level of $85 \mathrm{~g} / \mathrm{Mg}$, while the highest recovery $\left(\varepsilon_{\mathrm{k}}\right)$ and yield $(\gamma)$ were obtained for the highest dose of collector. The obtained results are consistent with the results presented in literature within the scope.

This work was done as a part of the University of Science and Technology scientific grant No. 15.11.100.079

\section{References}

1. M. Brozek, A. Mlynarczykowska, Physicochem. Probl. Miner. Process. 44, 23 (2010)

2. M. Brozek, A. Mlynarczykowska, Arch. Min. Sci., Vol. 57, No 3, p. 729-740 (2012)

3. J.A. Kitchener, Dev Miner. Process., 12, 1-39 (1992)

4. J. Konieczny, W. Pawlos, K.Ksiezniak, M. Krzeminska, E. Kasinska-Pilut, P.Piwowar, CUPRUM, 2(75), 87-95 (2015)

5. B.P. Kowalczuk, O. Sahbaz, J. Drzymala, . Minerals Engineering 24, 766-771 (2011)

6. A. J. Lynch, N. Johnson, E. V. Manlapig, C. G. Thorne, Dev. Miner. Process, 3 (1981)

7. A. Mlynarczykowska, A. Nyrek, K. Oleksik, IM, 1(35), 181-188 (2015)

8. A. Mlynarczykowska, A. Nyrek, K. Oleksik, IM, 18(1), 257-262 (2017)

9. M. K. Mpongo, E. Siame, AJST, 7(1) (2006)

10. J.D. Pease, D.C. Curry, M.F. Young, Minerals Engineering, 19, 831-840 (2006)

11. A. Potulska, doctoral thesis (Politechnika Wroclawska, Wydzial Geoinzynierii, Gornictwa i Geologii, Wroclaw, 2008)

12. D. Saramak, Mineral Resources Management, 28(4), 87-99, (2012)

13. D. Saramak, Physicochem. Probl. Miner. Process. 48(1), 219-226 (2012)

14. D. Saramak, R.A. Kleiv, Minerals Engineering, 4344, 105-111, (2013)

15. D. Saramak, A. Mlynarczykowska, A. Krawczykowska, Archives of Metallurgy and Materials., 59(3), 951-955, (2014)

16. D. Saramak, A. Krawczykowska, A. Mlynarczykowska, Arch. Min. Sci., 59(3), 731-740 (2014)

17. J. A. Solari, R. J. Gochin, , Dev Miner. Process., 12, 361-399 (1992)

18. R. Sousa, A. Futuro, C. Setas Pires, M. Machado Leite, Physicochem. Probl. Minerl. Process. 53(2), 758-769 (2017)

19. G. C. Thorne, E. V. Manlapig, J. S. Hall, A. J. Lynch, Flotation A. M Gaudin memorial, 2,725-752 (1976)

20. R. Tomanec, M. Blagojev, IM, 18(1), 165-172 (2017)

21. W.J. Trahar, Int. J. Miner. Process., 8(2), 289-32 (1981)

22. X. Luo, B. Feng, C. Wong, J. Miao, B. Ma, H. Zhou, JMRT, 5(2), 131 - 135 (2016) 